\title{
Nasopharyngeal Carcinoma: Prospects of Chemo radiation and Changing Trends in Epidemiology
}

\author{
Pradip Kumar Tiwari ${ }^{1 *}$ and Nabajyoti Saikia ${ }^{2}$ \\ ${ }^{1}$ Department of Otolaryngology and Head and Neck Surgery, Assam Medical College, India \\ ${ }^{2}$ Department of Otolaryngology and Head and Neck Surgery, India
}

Submission: April 06, 2017; Published: July 27, 2017

*Corresponding author: Pradip Kumar Tiwari, Resident, Department of Otolaryngology and Head and Neck Surgery, Assam Medical College, Dibrugarh, Assam, India, Tel: +91 9864988808/ +91 9435238702; Email: dr.pradiptiwari@gmail.com

Abstract

\section{Introduction}

Aim: Study the changing trend basically in the Upper - Assam region of India and its prospects.

Case setting and design: Retrospective study of patients presenting with Nasopharyngeal Carcinoma between the study period of one and a half year (Jan 2014 - Jun 2015) in the, Department of Otolaryngology and Head and Neck Surgery, Assam Medical College, Dibrugarh, Assam, India.

Materials and methods: Fourteen patients were treated in the study period. Different approaches were used.

Results: Nasopharyngeal carcinoma is not confined to any specific ethnic community or age, however bimodal peak was again proved and concurrent chemo-radiation therapy was better than other treatment modalities.

Conclusion: Bimodal peak occurrence of the disease should be emphasized and chemo radiation should be the treatment of choice.

\section{Introduction}

Nasopharyngeal carcinoma is a rare disease all over the world. It has often been less evaluated, misdiagnosed, partially treated, most commonly recurred and prognostically poor carcinoma. It has a bimodal peak with occurrence in the late second decades and in the fifth decades. Presently the incidence of nasopharyngeal carcinoma is low in most parts of the world. The rates are twice as high in males as in females [1]. There has been higher incidence of disease in certain parts of the world mainly south East Asia and southern China. Highest incidence has been reported among people of Guangdong province and Guangxi region of China where the incidence is around 50 or more per 100000 people per year [2]. There has been an increase in the incidence in the upper- Assam region of India. There has been an upsurge in the number of cases reporting to our department, Department of Otolaryngology and Head and Neck Surgery, Assam Medical College, Dibrugarh, Assam, India. Since the department caters to the need of most of the people residing in the Upper - Assam region of India, it can be well said that a changing trend has been seen in the incidence of the disease in recent times. Most of patients present with mass in the neck, nasal obstruction, hearing disorders, bleeding from nose. The most common presenting symptoms are severe, recurrent epistaxis with persistent nasal obstruction. As the disease progresses, facial pain and deformities, and cranial nerve palsies may occur. The diagnosis of nasopharyngeal carcinoma is essentially based on a careful history and nasal endoscopic examination, supplemented by imaging studies using computed tomogram (CT) and Magnetic Resonance Imaging (MRI). Aspiration cytology to establish histological diagnosis can be carried out. An increase in the reporting of cases was seen during the last year. Although the disease is more in southern Asia it has less relation with ethnicity rather than food habits and environmental set-up. The Naga people with an incidence of 4.3per 100000 people in the upper-Assam and nearby region has been the main concern of the various studies [3]. However other communities having the same cultural practices are now having a rise in the incidence of the disease. This is mainly due to the increase in the populated households and ill-ventilated houses, practicing of salted food- habits and the risk of EBV which is still in research. The present treatment is primarily radiation therapy followed by chemotherapy with cisplatin and other chemotherapy groups mainly docetaxel and 5FU. 


\section{Materials and Methods}

The study is a retrospective study. The main objective being to highlight the changing trend in the epidemiology, pathogenesis, diagnosis, medical management. Although the study period is short but it is important and a note should be taken about the actual scenario that is trending. In a span of one and a half year (Jan 14'- Jun 15') there has been alarming reporting of fourteen cases. Out of fourteen patients two were of age group 16- 19 years and others were of age group 40-75 years.

\section{Results}

\section{Epidemiology}

Out of 585 diagnosed cases of head and neck neoplasms 14 cases were of nasopharyngeal carcinoma. It was a study of 14 patients in a period of one and a half year. There was a bimodal peak of occurrence mainly 2 nd and 5 th decades.

\section{Region wise distribution:}

a) Dibrugarh- 6 no's of cases, 1 Female and 5 Males (6 Hindu ) (Gupta, Lachoom, Sawasi, Madrasi, Kalita, Priya).

b) Tinsukia-3 no's of cases, 2 Females and 1 Male (2 Hindu and1Muslim) (Sharma, Shah and Hussain).

c) Sivasagar- 2 no's of cases, 1 Female and 1 Male (2 Hindu) (Gogoi and Mohan).

d) Golaghat -1 no. of cases, 1 Male (1 Hindu) (Sahani).

e) Dhemaji - 1 no. of cases, 1 Male (1 Muslim) (Raja).

f) Jorhat -1 no. of cases, 1 Male (1 Muslim) (Hussain).

4.1.2.Environment: All the above mentioned districts are generally same as far as environment is concerned and all have a specific period of dry, hot and dusty weather during similar period of a year. Communities having the same cultural practices are now having a rise in the incidence of the disease. This is mainly due to the increase in the populated households and illventilated houses and practicing of salted food- habits.

\section{Pathogenesis}

Nasopharyngeal carcinoma is the most common malignant tumour of the nasopharynx. Microscopically, it is of three types

a) Keratinising squamous cell carcinoma.

b) Non-keratinising differentiated carcinoma.

c) Non-keratinising undifferentiated carcinoma.

Many nasopharyngeal carcinoma also contain lots of immune system cells, especially lymphocytes. The nonkeratinising undifferentiated carcinoma may contain many lymphocytes among the cancer cells and hence also known as lymphoepithelioma. It may be due to body's own immune mechanism. There is generally no change in the treatment protocol for the different types of carcinoma however the stage is more important than its type for predicting the prognosis.

\section{Clinical Features}

The clinical features can be broadly classified into Table 1 .

Table 1: The clinical features can be broadly classified.

\begin{tabular}{|c|c|c|c|}
\hline \multicolumn{2}{|c|}{ Symptoms } & \multicolumn{2}{c|}{ Signs } \\
\hline Nasal obstruction & $100 \%$ & Nasopharyngeal mass & $100 \%$ \\
\hline Recurrent epistaxis & $50 \%$ & $\begin{array}{c}\text { Nasal cavity and } \\
\text { nasopharyngeal mass }\end{array}$ & $75 \%$ \\
\hline Headache & $40 \%$ & Conductive deafness & $25 \%$ \\
\hline Speech defects & $50 \%$ & Purulent ear discharge & $25 \%$ \\
\hline Snoring & $40 \%$ & \multicolumn{2}{|c}{} \\
\hline Deafness & $75 \%$ & & \\
\hline
\end{tabular}

\section{Investigations}

Figure 1: CT scan of Head and Neck Region.

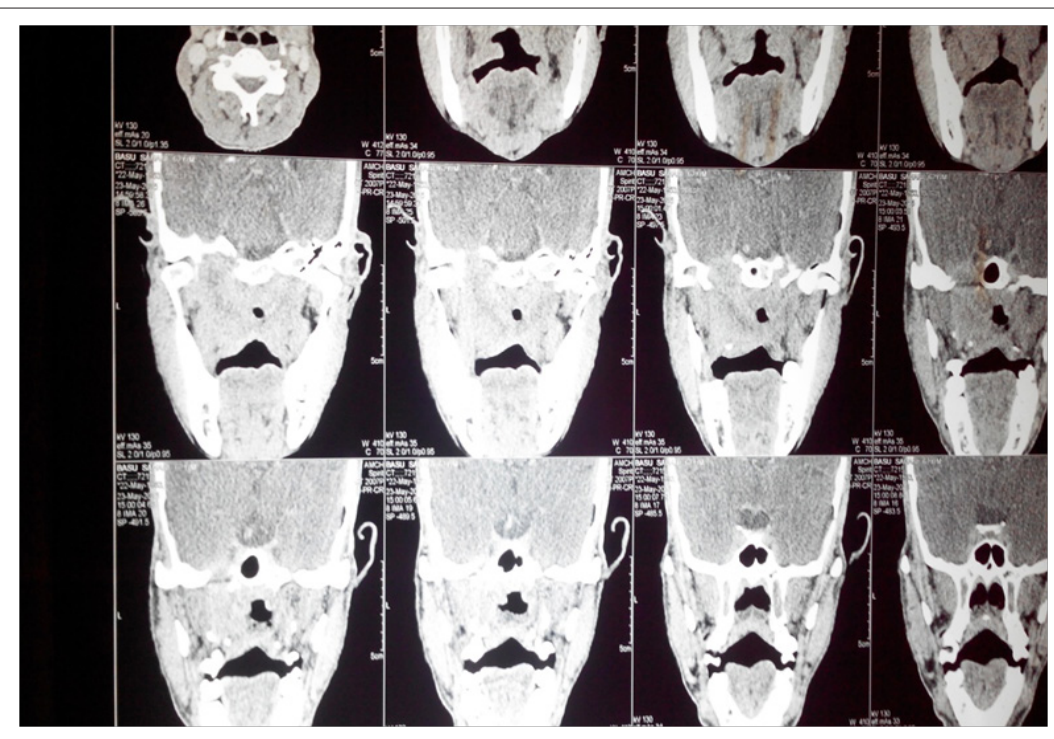




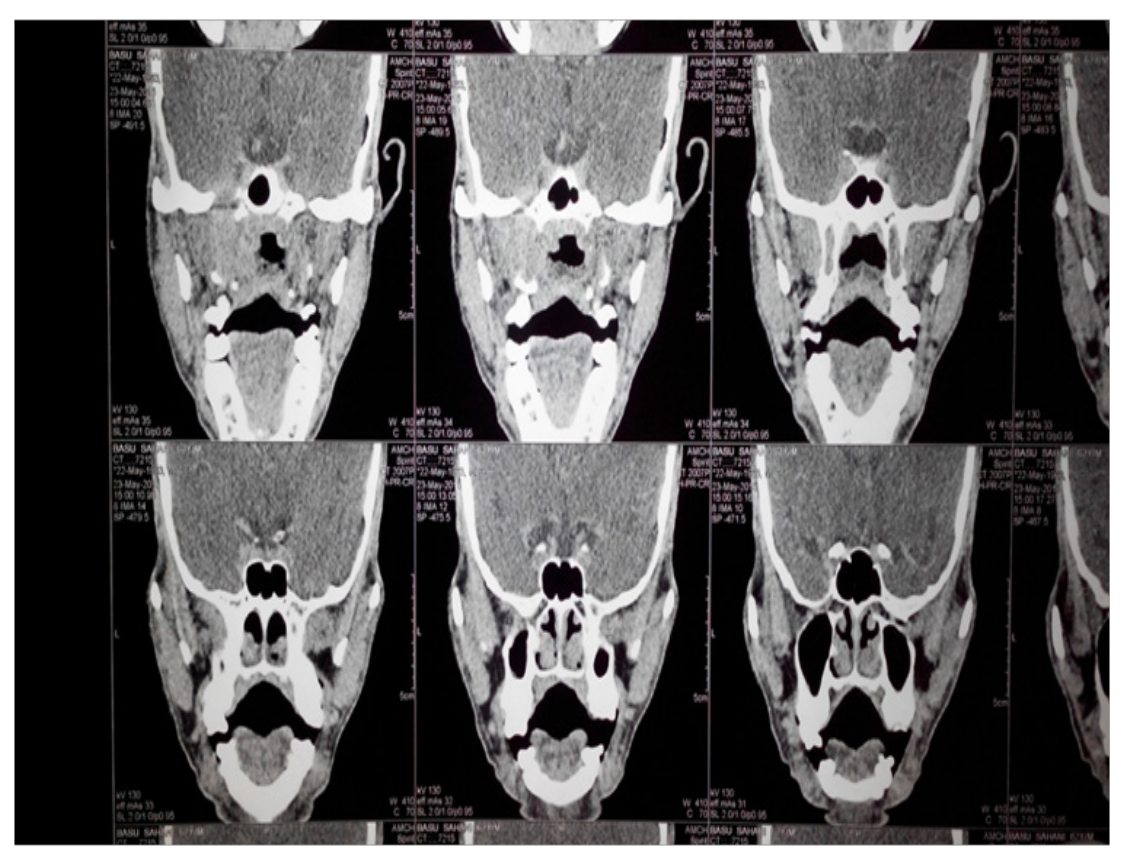

Figure 2: CT scan of Head and Neck Region.

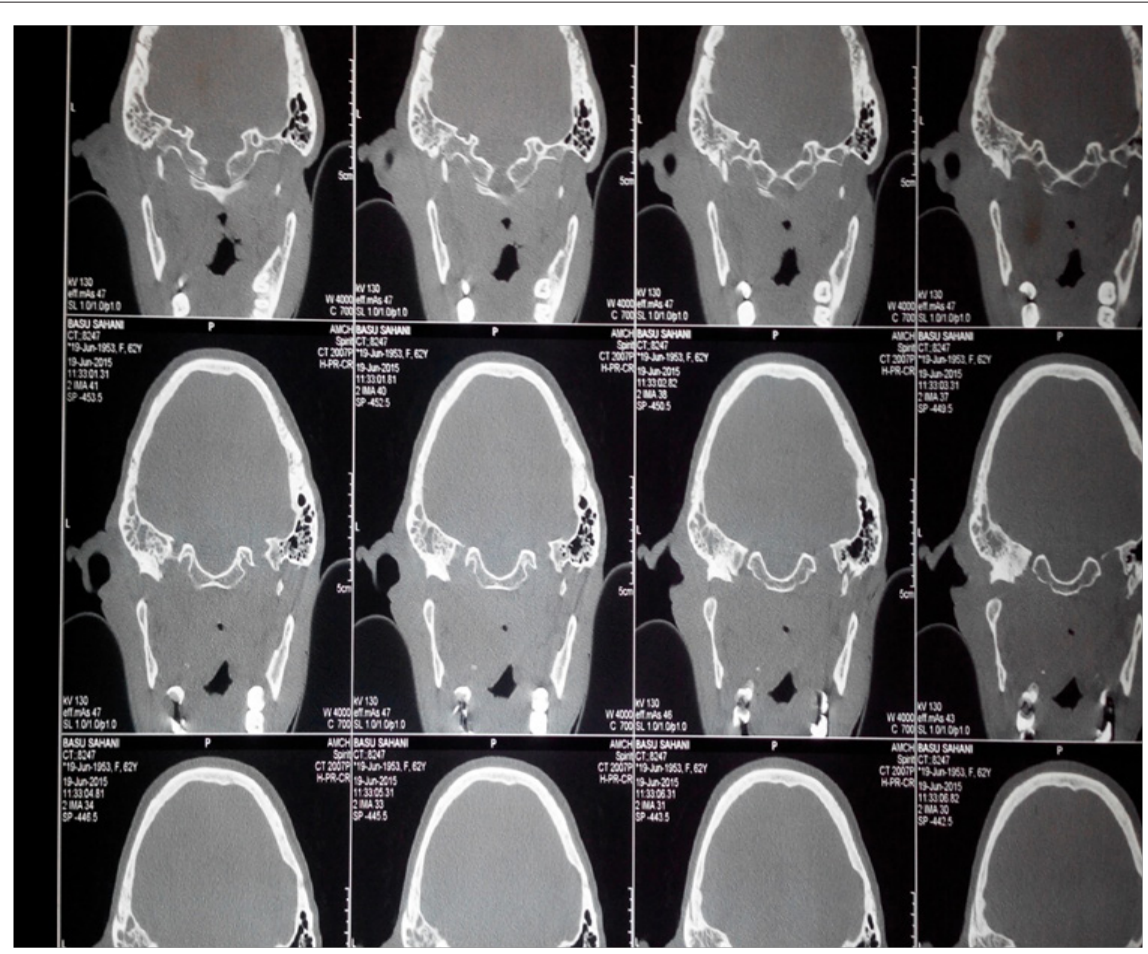

Figure 3: CT scan of Head and Neck Region.

All the cases were diagnosed first by diagnostic nasal endoscopies and then by radiological investigations mainly CT and MRI. In Figure 1-4 we can see that an ill defined soft tissue density growth showing heterogenous post-contrast enhancement is noted in the posterior nasopharynx involving the torus tubaris, fossa of Rosenmuller, prevertebral muscles. Superiorly the lesion is eroding the posterior aspect of left greater wing of sphenoid, left clinoid process, left petrous apex and infiltrating into the left cavernous sinus. Laterally the lesion is involving the pterygoid muscles and infiltrating into left infratemporal fossa and causing widening of the left stylomandibular foramen. Left cavernous sinus is bulky and heterogeneously enhancing. Decreased pneumatisation and increased sclerosis of left mastoid air cells is noted. Collection is noted in left mastoid air cells and left middle ear cavity. Routine blood examinations and other systemic laboratory examinations 
for the chemotherapy and radiotherapy were also performed in every case. In Figure 5 \& 6 we can see histopathologically that the malignant cells are arranged in small groups and syncytial sheets. Large numbers of lymphocytes and eosinophils leukocytes are also present. Large an a plastic epithelial cells with a considerable amount of cytoplasm and large vesicular nuclei in which there are one or more very prominent central nucleoli can be seen. Some of the tumor cells are binucleated.

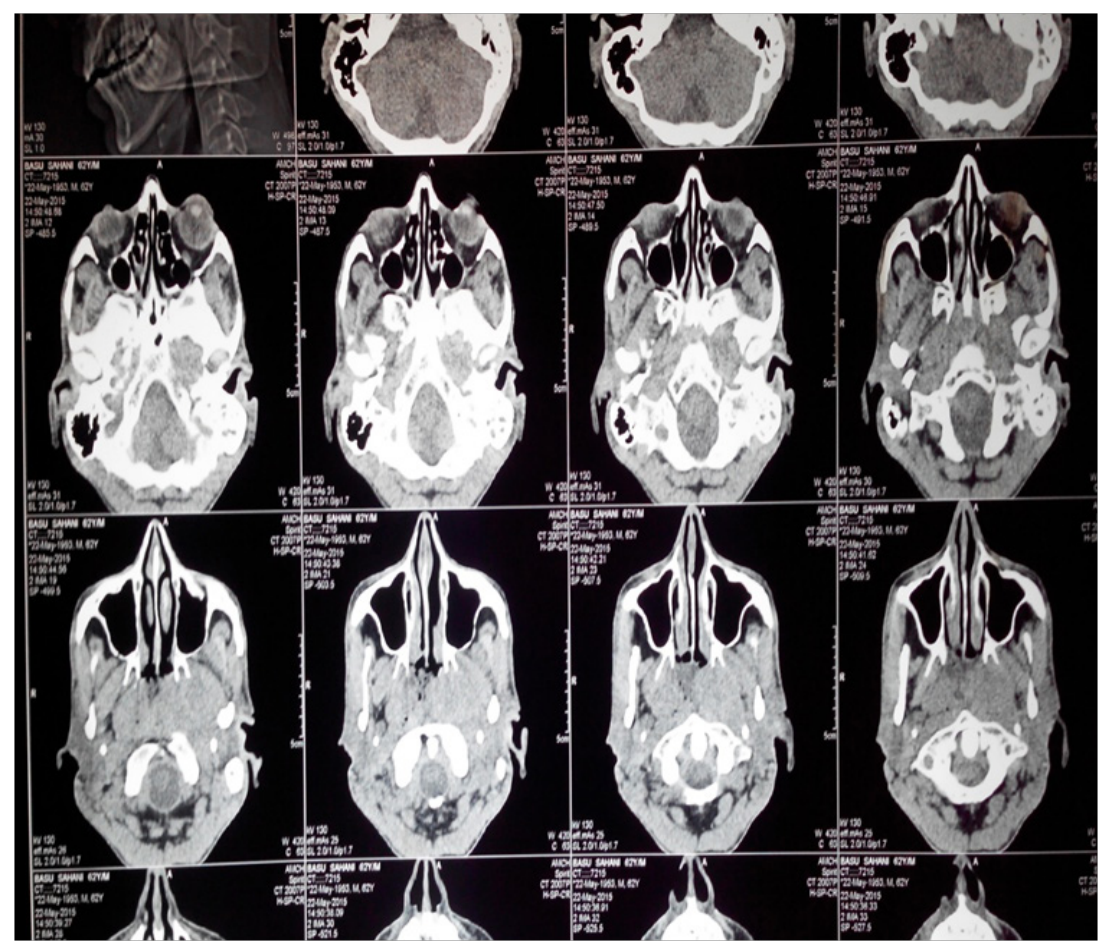

Figure 4: CT scan of Head and Neck Region.

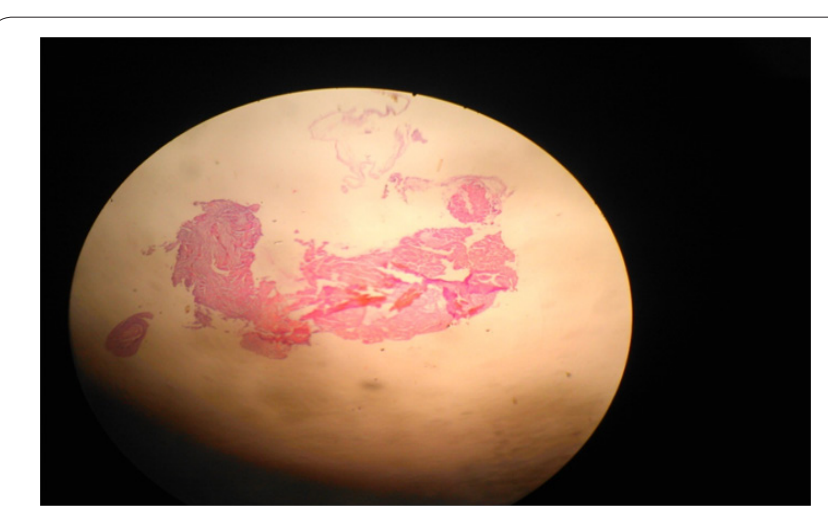

Figure 5: Microscopic Images of Nasopharyngeal Carcinoma (10X).

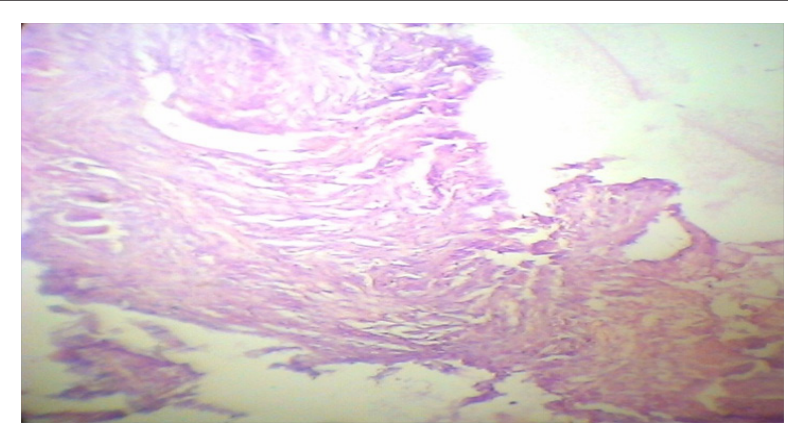

Figure 6: Microscopic Images of Nasopharyngeal Carcinoma (40X).

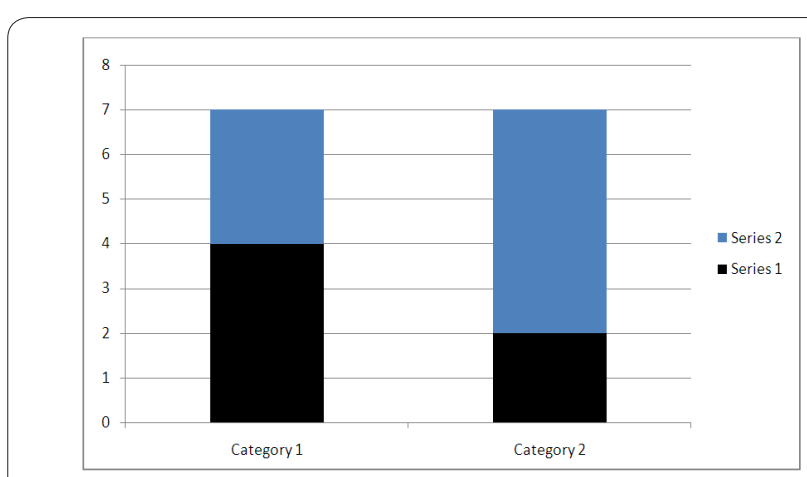

Figure 7: Category 1 showing Radiation alone and Category 2 Showing Concurrent Chemo radiation and Series 1 is Partial Response and Series 2 Complete Response.

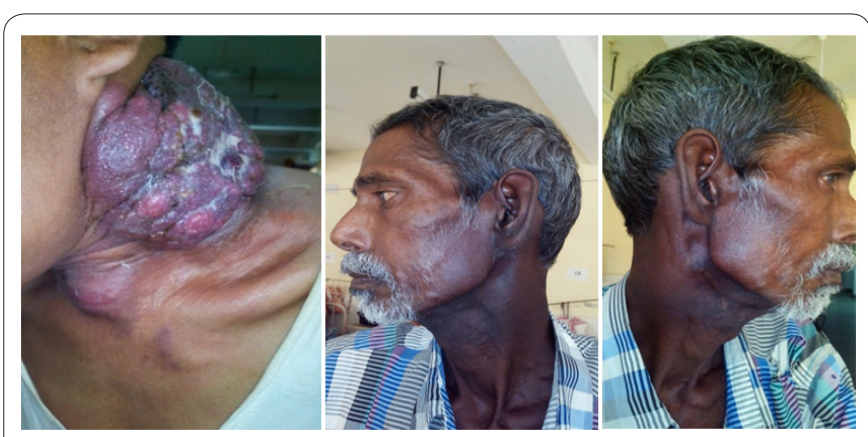

Figure 8: Images of Patients Showing the Metastatic Tumor and Results of Post Concurrent Chemo radiation. 


\section{Treatment Modalities}

All the cases were treated by chemo-radiation primarily radiation in 8 cases followed by chemotherapy and chemotherapy first followed by radiation in other 6 cases. Cisplatin based chemotherapy in a dose of $100 \mathrm{mg} / \mathrm{m} 2$ IV in 1 hour and Docetaxel in a dose of $100 \mathrm{mg} / \mathrm{m} 2 \mathrm{IV}$ in 1 hour on day 1 followed by Cisplatin chemotherapy in a dose of $100 \mathrm{mg} / \mathrm{m} 2$ IV in 1 hour on day 2 was given. Radiation in a dose of 66Gy -72Gy on weekdays for six weeks was given. Only one patient was treated by surgery and post-operative radiotherapy was used.

\section{Outcome}

Evaluation of the treatment outcome was done at the end of the induction chemotherapy and then after 6 weeks for concurrent chemo radiation. Complete tumor disappearance by shrinkage as investigated by CT scan was defined as complete response and tumour shrinkage by $50 \%$ or more but less than complete was taken as partial response. Patients were followed up clinically at 6 weeks after completion of treatment, then at 3 months thereafter.

Radiation alone arm 1: External-beam RT (ERT) was administered according to the techniques described. The nasopharynx, adjacent muscles and bones were treated to 66Gy in 33 fractions-2Gy per fraction, 5 days a week, in bilateral fields (two lateral faciocervical fields). The total duration of treatment lasted upto 6 weeks.

Concurrent Chemo radiotherapy arm-2: Patients randomized to the chemotherapy-radiotherapy arm were planned to receive Cisplatin 50mg infusion over 2 hours on a weekly basis during external radiotherapy, starting on the first day of radiotherapy. The complete blood picture was checked weekly before chemotherapy.

Evaluation: Tumor response was evaluated at the end of Induction Chemotherapy with a CT scan of Nasopharynx (including the retropharyngeal nodes) to assess the primary tumor, in addition to clinical measurement of neck lymph nodes. Toxicity was also evaluated. The same evaluation was carried out again at 6 weeks after completion of Cisplatin-RT as well as RT alone.

Observations and results: (Figure 7) fourteen patients with locally advanced Nasopharyngeal Carcinoma were included in this study. Of the 14 patients, 10 were male (71\%) and 4 females (29\%), with 7 patients in arm 1 and 7 patients in arm 2. Mean age was 46 years (18-75 years).

Assessment of Locoregional response to Induction CT revealed that complete response was seen in $57 \%$ of the patients. Partial response was seen in $43 \%$ of patients. Assessment of Loco regional response to Concurrent CT and RT revealed that complete response was seen in $64 \%$ of the patients. Partial response was seen in $36 \%$ of patients. No case showed progressive disease. Most common toxicity was anaemia followed by granulocytopenias, mucositis, stomatitis, vomiting and diarrhea. In two cases pre-existing chronic suppurative otitis media gave rise to post-auricular fistula formation. Patients of Arm 2 had higher percentage of toxicities. In Figure 8 we can see images of patients showing the metastatic tumour and results of post concurrent chemo radiation.

\section{Discussion}

Nasopharyngeal carcinoma is a malignant tumor with unique features that make it pathologically, epidemiologically, and clinically distinct from other head and neck cancers. There is no clear association with tobacco or alcohol use in most cases of nasopharyngeal cancer (World Health Organization [WHO] grades II and III). Patients with nasopharyngeal carcinoma have a higher incidence of nodal involvement and bilateral nodal disease at presentation, and overall (80\% to 90\%) nodal metastasis, as compared with patients with other malignancies of the head and neck. In addition, patients with nasopharyngeal carcinoma have a higher overall incidence of systemic metastasis than patients with tumors in other head and neck sites [4]. In some areas of the world, namely, southern China, Southeast Asia, North Africa, the Middle East, Alaska, and Greenland, nasopharyngeal cancer is more common. In these areas, incidence may be as high as 25 to 50 per 100,000 people [5]. Radiotherapy has been the traditional, standard form of therapy for all patients with local and loco regional disease. Marcial et al. [6] reported complete local clearance of nasopharyngeal carcinoma in $96 \%$ of patients with $\mathrm{T} 1$ disease treated with radiotherapy, $88 \%$ of those with $\mathrm{T} 2,81 \%$ of those with $\mathrm{T} 3$, and $74 \%$ of those with $\mathrm{T} 4$. Complete clearance rates in patients with N1-3 disease who received irradiation ranged from $93 \%$ to $71 \%$. The 5-year survival rate of these patients with nodal involvement was only 40\%; overall 5-year survival rates of patients with all stages of nasopharyngeal carcinoma treated with radiotherapy, reported by various investigators from all over the world, have ranged from $24 \%$ to $62 \%$ [6]. Qin et al. [7] reviewed the survival rates of 1,379 patients with advanced nasopharyngeal carcinoma treated with radiotherapy. The majority of patients had either stage III $(n=417)$ or stage IV cancer $(n=647)$. These investigators reported that the 5, 10-, and 20-year survival rates of patients with stage III cancers treated with radiotherapy alone were $46 \%, 29 \%$, and $17 \%$, respectively. The 5-, 10-, and 20 -year survival rates of stage IV patients treated with irradiation were $29 \%, 21 \%$, and $8 \%$, respectively. Overall, the 5 -year survival rate of nasopharyngeal carcinoma patients with stage IV disease treated with radiotherapy alone was less than $30 \%$, regardless of country of origin or histopathology. Loco regional recurrences occur in $40 \%$ to $80 \%$ of patients, and distant recurrences in $15 \%$ to $50 \%$ of patients. The usual radiation dose is 65 to $75 \mathrm{~Gy}$ in 1.8- to 2.0-Gy fractions, 5 days a week. This dose is crucial for achieving complete loco regional control and 5-year survival [7].

Nasopharyngeal carcinomas are highly sensitive to chemotherapy. Single agents identified as being active in 
this disease include methotrexate, bleomycin (Blenoxane), doxorubicin, cisplatin (Platinol), carboplatin (Paraplatin), and, more recently, paclitaxel (Taxol), and to a lesser extent, fluorouracil (5-FU) and the vinca alkaloids. For patients with head and neck cancers in general, and especially for those with nasopharyngeal carcinoma, combination chemotherapeutic regimens are more active than single drugs, and cisplatinbased combinations are more active than non cisplatin-based combinations $[8,9]$.

Many phase II trials of concurrent chemo radiotherapy in patients with locally advanced nasopharyngeal carcinoma have been reported [10-20]. Several chemotherapeutic agents, especially cisplatin [21-23], produce synergistic and/or additive effects when used with radiotherapy. One possible advantage of using concomitant cisplatin and radiotherapy in patients with head and neck cancers, as opposed to other agents, such as methotrexate, bleomycin, or 5-FU, is the lack of increased local side effects (especially mucositis). Most investigators gave standard one-fraction-per-day irradiation. The radiation dose was the same as without chemotherapy, i.e., $>6,400$ cGy in most cases. When the results of concomitant chemo radiotherapy were compared with those of historical matched control patients, most investigators reported improvements in local control, disease-free survival, and overall survival with the combined treatment. In an early study published by the Radiation Therapy Oncology Group (RTOG), Haythem et al. reported the results of concomitant treatment with single-agent cisplatin and radiotherapy in 124 patients with locally advanced, inoperable or unrespectable stage III $(n=24)$ or stage IV $(n=100)$ head and neck cancers; this study population included 28 patients with nasopharyngeal cancers, 27 of whom had stage IV disease. The cisplatin dose was $100 \mathrm{mg} / \mathrm{m} 2$, given intravenously with hydration and mannitol diuresis, once every 3 weeks, concurrent with standard radiation therapy to a total dose of up to 7,380cGy. Complete response rates were $70 \%$ for all patients and $89 \%$ for those with nasopharyngeal cancers $[19,20,24]$.

When the survival of patients with nasopharyngeal cancer was compared with survival of those with tumors of other head and neck sites (all were treated with the same chemo radiotherapy), a significantly higher survival rate was observed in the nasopharyngeal carcinoma patients. In addition, the survival of the nasopharyngeal carcinoma patients treated with concurrent cisplatin and radiotherapy was significantly better than the survival of historical matched controls treated with the same dose of radiotherapy alone [19,20,24].

\section{Conclusion}

Nasopharyngeal carcinoma although rare, should not be misdiagnosed as the available treatment is rewarding and there should not be any predetermined relation of the disease with any specific ethnic race or community as we have found in our study that it is associated with different types of ethnic race or community. There is also no point in waiting for individual line of treatment and concurrent chemo-radiation is better than any line of treatment.

\section{References}

1. Hirayama $T$ (1978) Descriptive and analytical epidemiology of nasopharyngeal cancer. In: de The G, Ito Y (Eds.), Nasopharyngeal Carcinoma: Etiology and Control. IARC Scientific Pub 20: 167.

2. Chan SH (1990) Aetiology of nasopharyngeal carcinoma. Ann Acad Med Singapore 19(2): 201-207.

3. Kumar S (2003) Epidemiological and etiological factors associated with nasopharyngeal carcinoma. ICMR Bulletin 33(9).

4. Ali H, Al-Sarraf M (2000) Chemotherapy in advanced nasopharyngeal cancer. Oncology (Williston Park) 14(8): 1223-1230.

5. Ho JH (1978) An epidemiological and clinical study of nasopharyngeal carcinoma. Int J Radiat Oncol Biol Phys 4(3-4): 182-198.

6. Marcial VA, Hanley JA, Chang C, Davis LW, Moscol JA (1980) Splitcourse radiation therapy of carcinoma of the nasopharynx: Results of a national collaborative clinical trial of the Radiation Therapy Oncology Group. Int J Radiat Oncol Biol Phys 6(4): 409-414.

7. Qin D, Hu Y, Yan J, Xu GZ, Cai WM, et al. (1988) Analysis of 1379 patients with nasopharyngeal carcinoma treated by radiation. Cancer 61(6): $1117-1124$

8. Decker DA, Drelichman A, Al-Sarraf M, Crissman J, Reed ML (1983) Chemotherapy for nasopharyngeal carcinoma: A ten year experience. Cancer 52(4): 602-605.

9. Choo R, Tannock I (1991) Chemotherapy for recurrent and metastatic carcinoma of the nasopharynx: A review of the Princess Margaret hospital experience. Cancer 68(10): 2120-2124.

10. Richards GJ, Chambers RG (1973) Hydroxyurea in the treatment of neoplasm of the head and neck. The American Journal of Surgery 126(4): 513-518.

11. Van Andel JG, Hop WC (1982) Carcinoma of the nasopharynx: Review of 86 cases. Clin Radiol 33(1): 95-99.

12. Huang SC, Lui LT, Lynn TC (1985) Nasopharyngeal cancer: Study III. A review of 1206 patients treated with combined modalities. Int J Radiat Oncol Biol Phys 11(10): 1789-1793.

13. Flores A, Dickson RI, Riding K, Coy P (1986) Cancer of the nasopharynx in British Columbia. Am J Clin Oncol 9(4): 281-291.

14. Souhami L, Babinowits M (1988) Combined treatment in carcinoma of the nasopharynx. Laryngoscope 98(8 Pt 1): 881-883.

15. Choi KN, Rotman M, Aziz H, Sohn CK, Schulsinger A, et al. (1997) Concomitant infusion cisplatin and hyperfractionated radiotherapy for locally advanced nasopharyngeal and paranasal sinus tumors. Int J Radiat Oncol Biol Phys 39(4): 823-839.

16. Pendjer I, Krejovic B, Vucicevic SA (1997) Comparative study of undifferentiated nasopharyngeal carcinoma treated with radiotherapy or combined treatment with zorubicin-cisplatin and radiotherapy. Eur Arch Otorhinolaryngol 254(Suppl 1): 127-129.

17. Maoleekoonpairoj S, Pharomratanapongse P, Puttanuparp S (1997) Phase II study: Concurrent chemoradiotherapy in advanced nasopharyngeal carcinoma. J Med Assoc Thai 80(12): 778-784.

18. Lin JC, Chen KY, Jan JS, Hsu CY (1996) Partially hyperfractionated accelerated radiotherapy and concurrent chemotherapy for advanced nasopharyngeal carcinoma. Int J Radiat Oncol Biol Phys 36(5): 11271136.

19. Al-Sarraf M, Zundmanis M, Marcial V (1986) Concurrent cisplatin and radiotherapy in patients with locally advanced nasopharyngeal carcinoma. RTOG study (abstract). Proc Am Soc Clin Oncol 5: 142. 
20. Al-Sarraf M, Pajak TF, Marcial VA, Mowry P, Cooper JS, et al. (1987) Concurrent radiotherapy and chemotherapy with cisplatin in inoperable squamous cell carcinoma of the head and neck. An RTOG study. Cancer 59(2): 259-265.

21. Douple EB, Richmond RC, Logan ME (1977) Therapeutic potentiation in a mouse mammary tumor and an intracerebral rat brain tumor by combined treatment with cis-dichlorodiammineplatinum (II) and radiation. J Clin Hematol Oncol 7: 585-603.

22. Soloway MS, Morris CR, Sudderth B (1979) Radiation therapy and cisdichlorodiammineplatinum (II) in transplantable and primary murine bladder cancer. Int J Radiat Oncol Biol Phys 5(8): 1355-1360.
23. Szumiel I, Nias AH (1976) The effect of combined treatment with a platinum complex and ionizing radiation on Chinese hamster ovary cells in vitro. Br J Cancer 33: 450-458.

24. Al-Sarraf M, Pajak TF, Cooper JS, Mohiuddin M, Herskovic, et al. (1990) A Chemo-radiotherapy in patients with locally advanced nasopharyngeal carcinoma: A Radiation Therapy Oncology Group study. J Clin Oncol 8(8): 1342-1351.

\section{Your next submission with Juniper Publishers will reach you the below assets}

- Quality Editorial service

- Swift Peer Review

- Reprints availability

- E-prints Service

- Manuscript Podcast for convenient understanding

- Global attainment for your research

- Manuscript accessibility in different formats

( Pdf, E-pub, Full Text, Audio)

- Unceasing customer service

Track the below URL for one-step submission https://juniperpublishers.com/online-submission.php 